\title{
Pengaruh Hedonic Shopping Terhadap Impulse Buying Yang Dimediasi Emosi Positif (Survei Pada Konsumen Toko Fashion di Kota "X")
}

\author{
Davota Ikanubun ${ }^{*}$ Sri Murni Setyawati2; Nur Choirul Afif ${ }^{3}$ \\ ${ }^{1}$ Magister Manajemen, Universitas Jenderal Soedirman, Indonesia \\ ${ }^{2}$ Dosen Fakultas Ekonomi dan Bisnis, Universitas Jenderal Soedirman, Indonesia \\ ${ }^{3}$ Dosen Fakultas Ekonomi dan Bisnis, Universitas Jenderal Soedirman, Indonesia \\ davotaikanubun@yahoo.com
}

\begin{abstract}
Abstrak
Jenis penelitian ini adalah explanatory reserach, tujuannya untuk mengetahui pengaruh hedonic shopping terhadap impulse buying yang dimediasi oleh emosi positif konsumen pada pembelian pakaian di toko fashion. Penelitian ini dilakukan di Kota " $\mathrm{X}$ " dengan sampel sebanyak 160 responden yang merupakan mahasiswa pada salah satu perguruan tinggi di Kota "X". Analisis data menggunakan regresi dengan mediasi untuk mengetahui pengaruh dari variabel hedonic shopping terhadap impulse buying, hedonic shopping terhadap emosi positif, emosi positif terhadap impulse buying, dan variabel hedonic shopping terhadap impulse buying yang dimediasi oleh emosi positif. Pengolahan data dengan menggunakan SPSS versi 17. Hasil penelitian menunjukkan bahwa hedonic shopping memiliki pengaruh yang signifikan terhadap impulse buying, hedonic shopping berpengaruh signifikan terhadap emosi positif, emosi positif berpengaruh signifikan terhadap impulse buying, dan emosi positif tidak berpengaruh signifikan memediasi hubungan antara hedonic shopping dengan impulse buying.

Kata kunci: hedonic shopping, emosi positif dan impulse buying.
\end{abstract}

\begin{abstract}
This type of research is explanatory research, the purpose of which is to find out the effect of hedonic shopping on impulse buying which is mediated by positive emotions of consumers in purchasing clothing in fashion stores. This research was conducted in Kota "X" with a sample of 160 respondents who were students at one of the universities in the City of "X". Data analysis uses mediation regression to determine the effect of hedonic shopping variables on impulse buying, hedonic shopping on positive emotions, positive emotions on impulse buying, and hedonic shopping variables on impulse buying which are mediated by positive emotions. Data processing using SPSS version 17. The results showed that hedonic shopping had a significant effect on impulse buying, hedonic shopping had a significant effect on positive emotions, positive emotions had a significant effect on impulse buying, and positive emotions did not significantly mediate the relationship between hedonic shopping and impulse buying.
\end{abstract}

Keywords: hedonic shopping, positive emotions and impulse buying.

\section{PENDAHULUAN}

Trend fashion berkembang terus, selalu berputar dan berubah-ubah sesuai perkembangan zaman, sehingga menjadi sebuah referensi gaya busana untuk mengganti penampilan dan meniru orang lain, dimana harga diri, pengaruh media dan pengaruh relasi yang mengatur seperti teman sebaya turut berpengaruh pada perilaku pembelian dari gaya berpakaian remaja (Jemli, 2013). Para wanita selalu ingin mencoba mengikuti tren baru agar tetap tampil lebih keren, lebih tetap percaya diri dan nyaman saat mengenakan busana atau pakaian yang dibelinya. Model baju akan memberikan kesan modis bila dipadukan dengan 
asesoris lainnya yang sesuai dengan gaya atau warna baju sehingga terkesan serasi, terlihat chic (indah), lebih feminim, anggun dan cantik terkait dengan penampilannya. Wanita modern kini memiliki peran yang lebih beragam, lebih dinamis dan terkesan bebas berekspresi, begitu pula mereka dalam berpenampilan. Fashion wanita saat ini semakin beragam dan mencerminkan kebebasan masing-masing individu untuk memperlihatkan gayanya. Sehubungan dengan peluang bisnis fashion maka pemasar harus dapat menganalisis sikap dan perilaku konsumen dalam berbelanja di sebuah toko/ritel.

Pemasar (marketers) perlu memanfaatkan momen ini sebagai kesempatan untuk menarik konsumen khususnya wanita yang masih muda dalam memasarkan produknya. Karena perannya yang lebih dominan dalam pengambilan keputusan ekonomi membuat para pemasar perlu memikirkan cara yang tepat untuk memahaminya sehingga bisa memengaruhi mereka dalam membeli produk atau menggunakan jasa yang disediakan baginya. Dalam memasarkan produknya maka produsen dan pengecer lebih memperhatikan apa yang menjadi pusat perhatian para wanita secara individu, terkait dengan ukuran tubuhnya, pakaian yang bermerek dan pada kesempatan tertentu yang penting bagi mereka (Rieke, Fowler, Chang dan Velikova, 2016). Marketers perlu membangun hubungan emosional dengan wanita terutama wanita usia remaja karena memiliki sifat yang lebih emosional dalam pengambilan keputusan pembelian serta mudah dipengaruhi selain itu mereka selalu ingin tampil lebih cantik dan menarik diantara sesamanya.

Pada penelitian ini peneliti mengkombinasikan variabel Hedonic Shopping dalam pengaruhnya terhadap Impulse Buying pada wanita menyangkut produk fashion yaitu pakaian dengan mediasi Emosi Positif. Berdasarkan latar belakang diatas maka penelitian ini diberi judul "Pengaruh Hedonic Shopping Terhadap Impulse Buying Yang Dimediasi Emosi Positif (Survei Pada Konsumen Toko Fashion di Kota "X")

Penelitian ini meneliti beberapa variabel yang diantaranya meliputi: hedonic shopping sebagai variabel independen, emosi positif sebagai variabel mediasi dan impulse buying sebagai variabel dependen. Dengan demikian maka dapat dirumuskan pertanyaan penelitian sebagai berikut: (1) Apakah hedonic shopping berpengaruh positif terhadap impulse buying? (2) Apakah hedonic shopping berpengaruh positif terhadap emosi positif? (3) Apakah emosi positif berpengaruh positif terhadap impulse buying? (4) Apakah emosi positif memediasi hubungan antara hedonic shopping terhadap impulse buying?

\section{TINJAUAN PUSTAKA}

\section{Impulse Buying}

Konsumen dalam melakukan kegiatan berbelanja seringkali melakukan pembelian yang melebihi rencana pembelian sebelumnya. Hal tersebut menunjukkan bahwa konsumen 
sering melakukan pembelian tidak terencana yang dikenal dengan sebutan impulse buying atau impulse purchase. Menurut Verplanken dan Sato (2011) bahwa impulse buying mengakibatkan konsumen akan membelanjakan barang-barang yang sebenarnya tidaklah direncanakan untuk dibeli sehingga terjadi pengeluaran lebih besar yang kemudian akan membuatnya merasa bersalah dan menyesal, hal ini dianggap sebagai hasil dari keputusan yang tidak masuk akal atau irasional. Weinberg dan Gottwald (1982) berpendapat bahwa Impulse buying dipengaruhi oleh beberapa faktor, antara lain: faktor internal dan faktor eksternal. Dimana faktor internal yaitu faktor-faktor yang terdapat pada diri seseorang, faktor ini menyangkut suasana hati dan kebiasaan mereka saat berbelanja sedangkan faktor eksternal merupakan faktor pengaruh dari suasana lingkungan toko dan promosi yang ditawarkan oleh toko. Mohan, Sivakumaran and Sharma (2013) menemukan juga bahwa melalui pengaruh yang positif dan dorongan dari suasana lingkungan toko maupun kepribadian konsumen turut memengaruhi keputusan pembelian yang tidak direncanakan.

Pembelian yang tidak direncanakan yang karakteristiknya adalah pengambilan keputusan dilakukan relatif singkat dan adanya keinginan untuk memilikinya dengan segera. Variabel yang diukur dengan pernyataan: (1) Pembelian pakaian dilakukan secara spontan; (2) Pembelian pakaian sebagai hadiah atau sumbangan; (3) Pembeli membeli pakaian tanpa dipikir terlebih dahulu; (4) Ketika pembeli melihat pakaian langsung membelinya; (5) Pembelian pakaian secara terburu-buru; (6) Pembelian pakaian dilakukan sesuai perasaannya saat itu; (7) Pembelian dilakukan tanpa dipikirkan dan direncanakan; dan (8) Membeli pakaian tanpa dilihat dan dicoba terlebih dahulu.

\section{Hedonic Shopping}

Menurut Scarpi dalam Kosyu, Hidayat dan Abdillah, 2014 bahwa Hedonic shopping oleh Hirschman dan Holbrook, dalam Alba and Williams (2012) merupakan rasa gembira, rasa ingin tau yang lebih, khayalan mereka yang membuat mereka merasa senang dan gembira saat berbelanja serta hal-hal yang membuat mereka terangsang dan senang dalam menggunakan produk tersebut juga sesuatu yang menarik seperti indah, bagus dan unik, hal ini merupakan nilai dari pengalaman dalam kegiatan berbelanja yang mereka lakukan. Pada saat konsumen berbelanja maka konsumen tentu saja akan memperhatikan aspek-aspek yang terkait dengan kesenangan dan kenikmatan yang disebut hedonik tersebut. Hedonic consumption mencerminkan instrumen yang menyajikan secara langsung manfaat dari suatu pengalaman dalam melakukan pembelanjaan, seperti kesenangan dan hal-hal baru (Samuel, 2005). Konsumsi hedonik pada fashion akan mengarahkan konsumen pada pembelian yang tidak direncanakan sebagai akibat dari pengaruh dan dorongan yang kuat dan positif (Saran et al., 2016). Dimana konsumen lebih cepat dalam pengambilan keputusan dalam belanja fashion 
karena didorong oleh keinginan dari dalam dirinya yang terus mendorongnya untuk membeli, selain itu juga karena rasa senang yang dirasakannya (Park dan Lennon, 2006).

Perilaku konsumen yang berhubungan dengan mencari kesenangan, rasa ingin tau yang tinggi serta mencari hiburan yang menyebabkannya melakukan pembelian impuls. Variabel yang diukur dengan pernyataan: (1) Pembeli sangat menikmati perjalanan berbelanja; (2) Pembeli suka membeli pakaian; (3) Rasa penasaran pembeli akan adanya pakaian dengan model terbaru di toko yang dikunjungi; dan (4) Berbelanja pakaian dilakukan untuk melupakan masalahnya.

\section{Emosi Positif}

Emosi merupakan suasana hati seseorang yang juga turut berpengaruh dalam melakukan keputusan pembelian terhadap suatu barang, dimana suasana hati tersebut merupakan salah satu faktor yang juga berperan penting (Park, Kim and Forney, 2006). Menurut Hawkins dan Mothersbaugh (2014) bahwa emosi positif merupakan suasana hati atau perasaan yang dialami seseorang, terus mendorong seseorang dan sangat kuat sehingga tidak dapat dikendalikan dan selalu mempengaruhi perilaku seseorang. Saran, Roy and Sethuraman (2016) penelitiannya menunjukkan bahwa konsumen saat berbelanja fashion akhirnya akan melakukan impulse buying karena dipengaruhi keinginan dan dorongan mereka untuk memiliki yang lebih tinggi, rasa senang, suka serta ketertarikan pada fashion tersebut. Konsumen yang dengan leluasa dalam menunjukkan perasaan gembira dan bahagianya akan cenderung dan lebih dominan untuk melakukan impulse buying di tempat perbelanjaan, dengan demikian maka emosional konsumen berperan penting hal keputusan pembelian pada pakaian secara impulsif (Dewi, Suharyono dan Srikandi, 2015).

Perasaan atau mood positif yang dialami seseorang yang mendorongnya untuk melakukan pembelian tidak terencana. Variabel yang diukur dengan pernyataan: (1) Rasa senang berbelanja oleh pembeli di toko fashion; (2) Rasa puas berbelanja oleh pembeli di toko fashion; (3) Rasa nyaman berbelanja oleh pembeli di toko fashion; dan (4) Rasa bersemangat berbelanja oleh pembeli di toko fashion.

Berdasarkan penjelasan diatas maka model penelitian dan hipotesis penelitiannya adalah sebagai berikut:

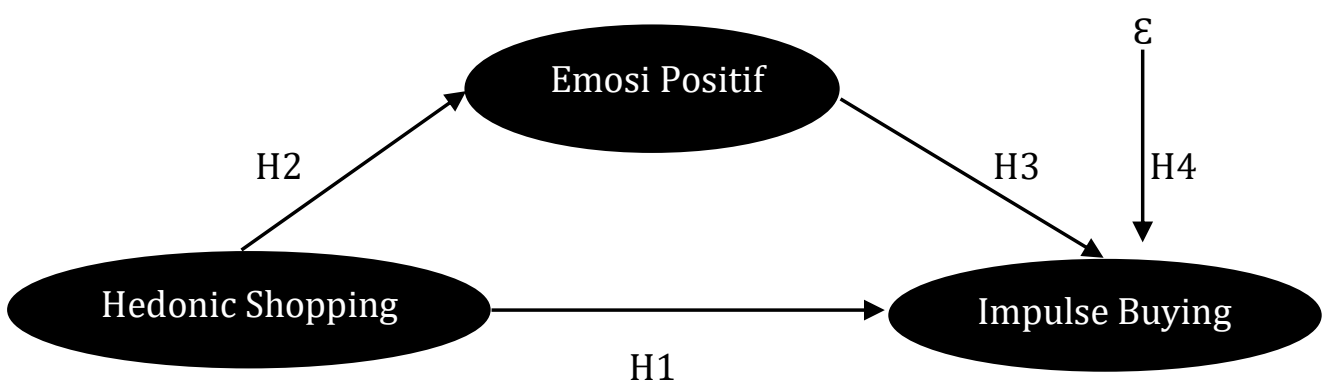

Gambar 1 Model Penelitian 
H1 : Shopping hedonic berpengaruh positif terhadap impulse buying

H2 : Shopping hedonic berpengaruh positif terhadap emosi positif

H3 : Emosi positif berpengaruh positif terhadap impulse buying.

H4 : Emosi positif memediasi hubungan antara hedonic shopping terhadap impulse buying

\section{METODE PENELITIAN}

Jenis penelitian ini adalah explanatory research dengan pendekatan kuantitatif. Kuesioner merupakan alat yang digunakan untuk mengumpulkan data. Teknik analisis data menggunakan regresi sederhana untuk melihat pengaruh dari masing-masing variabel penelitian. Pengolahan data menggunakan SPSS versi 17.

Penelitian ini merupakan penelitian empiris, dimana penelitian dilakukan dengan mengambil sampel penelitian dari suatu populasi dengan alat pengumpulan data adalah kuesioner. Sampel pada penelitian ini adalah mahasiswa wanita Fakultas Ekonomi dan Bisnis Jurusan Manajemen pada salah satu universitas yang merupakan pelanggan pada toko fashion di Kota "X" sebanyak 160 orang. Teknik pengambilan sampel adalah purposive sampling. Pada penelitian ini peneliti menggunakan Skala Likert's lima point sebagai alternatif jawaban untuk mengukur masing-masing variabel dalam penelitian ini.

\section{HASIL DAN PEMBAHASAN}

Kuesioner yang disebarkan kepada responden seluruhnya berjumlah 170 kuesioner, namun yang kembali dan dapat diolah lebih lanjut adalah sebanyak 160 kuesioner. Kuesioner disebarkan pada Mahasiswa Fakultas Ekonomi dan Bisnis Jurusan Manajemen dan diisi oleh responden yang berjenis kelamin perempuan yang berbelanja pakaian pada toko fashion di kota "X". Responden merupakan mahasiswi dari Fakultas Ekonomi dan Bisnis Jurusan Manajemen. Dari jumlah 160 tersebut, responden berada diantara kisaran umur 17 sampai dengan 36 tahun dengan presentasenya dapat diihat pada tabel berikut:

Tabel 1 Responden Berdasarkan Usia

\begin{tabular}{ccc}
\hline Umur (Tahun) & Jumlah & Persentase \\
\hline $17-19$ & 51 Responden & $31,88 \%$ \\
$20-24$ & 101 Responden & $63,13 \%$ \\
$25-29$ & 5 Responden & $3,12 \%$ \\
$>30$ & 3 Responden & $1,87 \%$ \\
\hline Total & 160 Responden & $100 \%$ \\
\hline
\end{tabular}

Sumber: Data Primer diolah, 2018

\section{Validitas Kuesioner Penelitian}

Hasil dari uji validitas kuesioner untuk lebih jelasnya dapat dilihat pada tabel berikut: 
Tabel 2 Uji Validitas Konvergen

\begin{tabular}{lccc}
\hline Konstruk & Indikator & Faktor Loading & Keterangan \\
\hline \multirow{3}{*}{ Emosi Positif } & X1Q1 & $0,774^{* *}$ & Valid \\
& X1Q2 & $0,790^{* *}$ & Valid \\
& X1Q3 & $0,738^{* *}$ & Valid \\
X1Q4 & $0,746^{* *}$ & Valid \\
\hline \multirow{5}{*}{ Hedonic Shopping } & X2Q1 & $0,632^{* *}$ & Valid \\
& X2Q2 & $0,692^{* *}$ & Valid \\
& X2Q3 & $0,730^{* *}$ & Valid \\
& X2Q4 & $0,773^{* *}$ & Valid \\
\hline \multirow{5}{*}{ Impulse Buying } & YQ1 & $0,557^{* *}$ & Valid \\
& YQ2 & $0,604^{* *}$ & Valid \\
& YQ3 & $0,663^{* *}$ & Valid \\
& YQ4 & $0,739^{* *}$ & Valid \\
& YQ5 & $0,679^{* *}$ & Valid \\
& YQ6 & $0,730^{* *}$ & Valid \\
& YQ7 & $0,721^{* *}$ & Valid \\
\hline
\end{tabular}

Sumber: Data Primer diolah, 2018

Uji validitas juga dilakukan untuk semua variabel yang digunakan dalam penelitian ini, masing-masing item memiliki nilai Sig. 0,000 > 0,05. Angka tersebut menunjukkan bahwa seluruh item pertanyaan yang diusulkan untuk digunakan dalam penelitian ini adalah valid sehingga layak digunakan sebagai alat ukur dalam penelitian ini.

\section{Reliabilitas Kuesioner}

Output dari uji reliabilitas dapat dilihat pada tabel berikut:

Tabel 3 Reliabilitas Variabel Penelitian

\begin{tabular}{llccl}
\hline No. & Nama Variabel & $\begin{array}{l}\text { Jumlah } \\
\text { Pertanyaan }\end{array}$ & $\begin{array}{l}\text { Cronbach } \\
\text { Alpa }\end{array}$ & Keterangan \\
\hline 1. & Emosi Positif & 4 & 0,759 & Reliabel \\
2. & Hedonic Shopping & 4 & 0,659 & Reliabel \\
3. & Impulse Buying & 8 & 0,825 & Reliabel \\
\hline
\end{tabular}

Sumber: Data Primer diolah SPSS, 2018.

Output dari uji reliabilitas yang tertera pada tabel 3 menunjukkan bahwa nilai Cronbach Alpha pada variabel penelitian hedonic shopping sebesar 0,659, emosi positif sebesar 0,759, dan impulse buying sebesar 0,825 dimana semuanya memiliki nilai yang lebih besar dari 0,60. Sehingga disimpulkan bahwa instrumen dari semua variabel pada penelitian ini adalah reliabel dengan tingkat reliabilitas yang berbeda-beda.

\section{Hasil Analisis Regresi}

Penelitian ini menggunakan model persamaan regresi dengan mediasi. Dimana penelitian ini akan menguji pengaruh langsung hedonic shopping terhadap impulse buying, hedonic shopping terhadap emosi positif, emosi positif terhadap impulse buying, dan emosi positif memediasi hubungan antara hedonic shopping terhadap impulse buying. Pengujian 
dilakukan dengan metode Kausal Step dan menggunakan bantuan Statistical Package for the Social Sciences (SPSS) versi 17, dengan hasilnya sebagai berikut:

Persamaan I, hedonic shopping berpengaruh signifikan terhadap impulse buying ( $\mathrm{c} \neq 0$ )

$\hat{\mathrm{Y}}=\alpha_{1}+\mathrm{cX}+\mathrm{e}$

$\hat{Y}=6,495+0,519 X+e$

Penjelasannya: (1) Konstanta sebesar 6,495 artinya jika hedonic shopping sebesar 0 (nol), maka impulse buying sebesar 6,495 dan (2) Koefisien regresi c atau hedonic shopping sebesar 0,519 artinya jika hedonic shopping mengalami kenaikan satu satuan, maka impulse buying akan mengalami peningkatan 0,519 dengan signifikansi 0,000 lebih kecil dari $\alpha$ 0,05 dengan arah koefisien positif yang berarti terdapat pengaruh positif dan signifikan hedonic shopping terhadap impulse buying.

Persamaan II, hedonic shopping berpengaruh signifikan terhadap emosi positif $(a \neq 0)$

$\dot{\mathrm{M}}=\alpha_{2}+\mathrm{aX}+\mathrm{e}$

$\hat{\mathrm{M}}=8,071+0,559 \mathrm{X}+\mathrm{e}$

Penjelasannya: (1) Konstanta sebesar 8,071 artinya jika hedonic shopping sebesar 0 (nol), maka emosi positif sebesar 8,071 dan (2) Koefisien regresi a atau hedonic shopping sebesar 0,559 artinya jika hedonic shopping mengalami kenaikan satu satuan, maka impulse buying akan mengalami peningkatan 0,559 dengan signifikansi 0,000 lebih kecil dari $\alpha$ 0,05 dengan arah koefisien positif yang berarti terdapat pengaruh positif dan signifikan hedonic shopping terhadap emosi positif.

Persamaan III, emosi positif berpengaruh signifikan terhadap impulse buying $(\mathrm{b} \neq 0)$

$\hat{\mathrm{Y}}=\alpha_{3}+\mathrm{bM}+\mathrm{e}$

$\hat{\mathrm{Y}}=10,895+0,319 \mathrm{M}+\mathrm{e}$

Penjelasannya: (1) Konstanta sebesar 10,895 artinya jika emosi positif sebesar 0 (nol), maka impulse buying sebesar 10,895 dan (2) Koefisien regresi b atau emosi positif sebesar 0,319 artinya jika emosi positif mengalami kenaikan satu satuan, maka impulse buying akan mengalami peningkatan 0,319 dengan signifikansi 0,000 lebih kecil dari $\alpha$ 0,05 dengan arah koefisien positif yang berarti terdapat pengaruh positif dan signifikan emosi positif terhadap impulse buying.

Persamaan IV, emosi positif memediasi hubungan antara hedonic shopping terhadap impulse buying $(\mathrm{b} \neq 0)$

$\hat{\mathrm{Y}}=\alpha_{4}+\mathrm{c}^{\prime} \mathrm{X}+\mathrm{bM}+\mathrm{e}$

$\hat{Y}=5,622+0,495 \mathrm{X}+0,043 \mathrm{M}+\mathrm{e}$

Penjelasannya: (1) Konstanta sebesar 5,622 artinya jika hedonic shopping dan emosi positif sebesar 0 (nol), maka impulse buying sebesar 5,622 dan (2) Koefisien regresi b atau emosi positif sebesar 0,043 dengan signifikansi 0,605 lebih besar dari $\alpha$ 0,05 dan nilai koefisien $c^{\prime}$ atau 
hedonic shopping sebesar 0,495 dengan signifikansi 0,000 lebih kecil dari $\alpha 0,05$. Artinya emosi positif memediasi hedonic shopping terhadap impulse buying secara parsial (partial mediation), dimana setelah memasukkan variabel emosi positif, pengaruh hedonic shopping terhadap impulse buying menurun tetapi tidak menjadi nol $\left(c^{\prime} \neq 0\right)$ atau pengaruh hedonic shopping terhadap impulse buying yang awalnya signifikan (sebelum memasukkan emosi positif) menjadi tetap signifikan setelah memasukkan emosi positif ke dalam model persamaan regresi, tetapi mengalami penurunan koefisien regresi $\left(c^{\prime}<c\right)$. Gambar model persamaan regresinya adalah sebagai berikut:

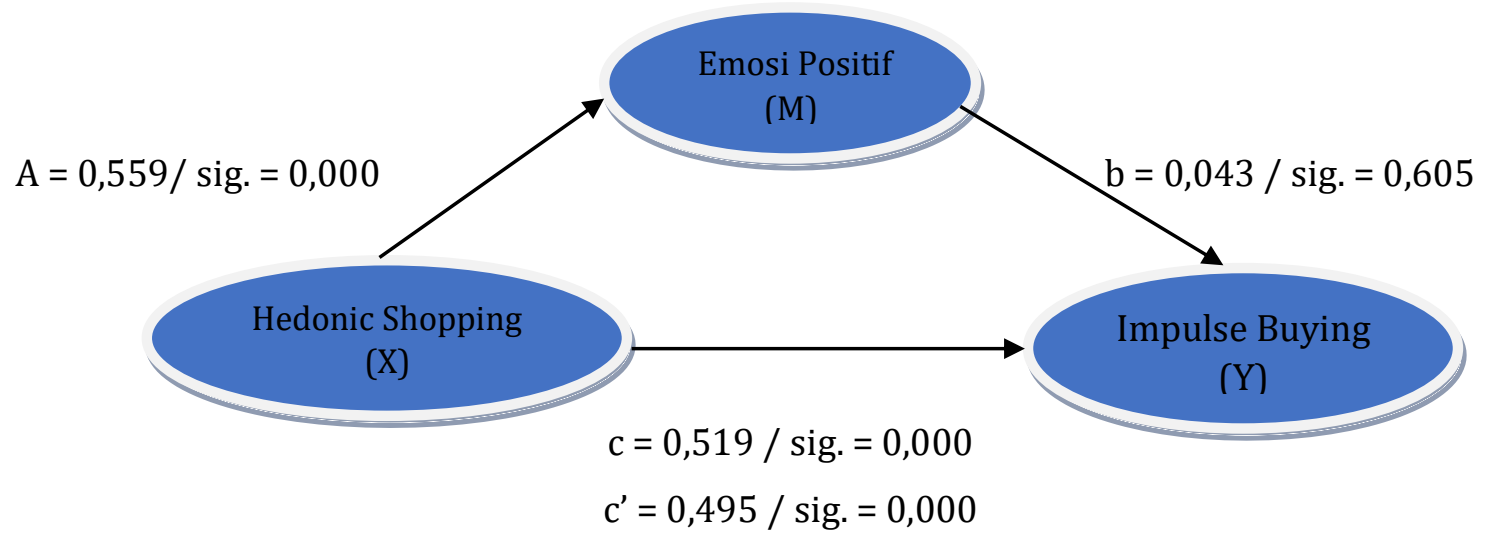

Gambar 2 Persamaan Regresi dengan Mediasi

Berdasarkan hasil analisis persamaan regresi emosi positif memediasi hubungan hedonic shopping terhadap impulse buying, maka dibuat pengaruh langsung dan tidak langsung dari hedonic shopping dan emosi positif terhadap impulse buying, dengan hitungan sebagai berikut: Pengaruh langsung $=0,495 \times 0,495=0,245=24,5 \%$

Pengaruh tidak langsung $=0,495 \times 0,559 \times 0,043=0,012=1,19 \%$

Pengaruh total $=24,5 \%+1,19 \%=25,69 \%$

Dari hasil perhitungan tersebut, pengaruh langsung hedonic shopping terhadap impulse buying adalah sebesar $24,5 \%$ dan pengaruh tidak langsung sebesar 1,19\%, sehingga pengaruh totalnya sebesar 25,69\%. Artinya pengaruh langsung > dari pengaruh tidak langsung, sehingga kesimpulannya emosi positif tidak memediasi hubungan antara hedonic shopping dengan impulse buying, yang dikarenakan pengaruh langsung lebih besar dari pengaruh tidak langsung.

Pembahasan

H1: Hedonic shopping berpengaruh signifikan terhadap impulse buying pada konsumen toko fashion di Kota "X". Terdapat pengaruh yang signifikan antara variabel hedonic shopping terhadap impulse buying konsumen, dimana hedonic shopping merupakan salah satu faktor dari terciptanya impulse buying konsumen. Seorang pembeli/ konsumen akan merasa menikmati perjalanan berbelanja, dan suka berbelanja pakaian pada toko fashion jika toko tersebut selalu 
menyediakan pakaian dengan model terbaru dan lengkap, harga yang terjangkau, sarana dan prasarana yang mendukung kegiatan berbelanjanya. Sarana dan prasarana tersebut akan memberikan rasa senang dan nyaman kepada pembeli sehingga dengan sendirinya akan mendorongnya untuk melakukan impulse buying.

Hasil penelitian ini ternyata sejalan dengan penelitian dari Saran et al., 2016 dalam temuannya bahwa konsumsi hedonis terhadap produk fashion memiliki pengaruh yang kuat dan positif terhadap pembelian impulsif atau tidak direncanakan. Hal ini bertentangan dengan Park et al., (2006) yang mana dalam penelitiannya menunjukkan hasil yang bertolak belakang dengan beberapa peneliti lainnya dimana tidak terdapat pengaruh yang signifikan dari kecenderungan konsumsi hedonis terhadap pembelian impuls berorientasi fashion. Dimana pengujian hipotesis yang dilakukan untuk mengetahui pengaruh hedonic shopping konsumen terhadap impulse buying menunjukkan nilai sig. $<0,05$ sehingga hipotesis diterima. Tingginya impulse buying konsumen menaikkan pendapatan bagi toko/ritel sebagai akibat dari hedonic shopping konsumen yang tinggi sebagai sumber pendapatan bagi toko/ritel. Sehingga hipotesis untuk variabel hedonic shopping terhadap impulse buying menunjukkan bahwa H0 ditolak dan Ha diterima.

\section{H2: Hedonic shopping berpengaruh signifikan terhadap emosi positif pada konsumen}

toko fashion di Kota " $\mathrm{X}$ ". Pengaruh signifikan antara variabel hedonic shopping terhadap emosi positif konsumen menunjukkan bahwa dalam belanja hedonis konsumen akan menunjukkan rasa senang, gembira dan puas yang lebih tinggi, dimana rasa ingin tau akan produk-produk fashion terbaru, memasuki tempat penjualan fashion terbaru dan pengalaman baru yang mereka dapatkan, sehingga berbelanja fashion akan berdampak bagi timbulnya emosi positif bagi konsumen.

Hasil penelitian ini sejalan dengan penelitian Rachmawati (2009) dan Amiri et al., (2012), yang menunjukkan bahwa ketika konsumen memiliki belanja hedonik yang baik pada toko fashion maka akan menghasilkan emosi positif (rasa senang, nyaman, puas dan bersemangat) yang lebih tinggi atau lebih banyak berbelanja fashion. Pengujian hipotesis yang dilakukan untuk mengetahui pengaruh hedonic shopping terhadap emosi positif konsumen menunjukkan nilai sig. $<0,05$ sehingga hipotesis diterima. Tingginya tingkat hedonic shopping akan meningkatkan emosi positif konsumen saat berbelanja di toko fashion. Sehingga hipotesis untuk variabel hedonic shopping terhadap emosi positif menunjukkan bahwa $\mathrm{HO}$ ditolak dan $\mathrm{Ha}$ diterima.

H3: Emosi positif berpengaruh signifikan terhadap impulse buying konsumen pada konsumen toko fashion di Kota "X". Pengaruh yang signifikan antara emosi positif terhadap impulse buying konsumen menunjukkan tingginya impulse buying konsumen yang disebabkan oleh tingginya emosi positif konsumen dalam pembelian pakaian pada toko fashion. Pengalaman 
menyenangkan yang dirasakan konsumen selama berbelanja di toko fashion (perasaan senang, puas dan nyaman dalam berbelanja) maka akan memengaruhi konsumen untuk membeli secara impulsif dan berkunjung kembali ke toko fashion. Dengan demikian maka kemungkinan untuk melakukan impulse buying semakin besar pada toko fashion yang dikunjungi.

Penelitian ini sejalan dengan hasil penelitian yang dikemukakan oleh Pattipeilohy, Rofiati, dan Idrus (2013) bahwa perilaku impulse buying secara langsung dipengaruhi oleh emosi positif yang ditunjukkan oleh konsumen melalui rasa senang, puas, nyaman, dan bersemangat yang mereka tunjukkan pada saat pembelian produk pakaian. Pengujian hipotesis yang dilakukan untuk mengetahui pengaruh emosi positif konsumen terhadap impulse buying menunjukkan nilai sig. $<0,05$ sehingga hipotesis diterima. Tingginya tingkat impulse buying konsumen meningkatkan pendapatan bagi toko/ritel sebagai akibat dari emosi positif konsumen yang tinggi sebagai sumber pendapatan toko/ritel. Sehingga hipotesis untuk variabel emosi positif terhadap impulse buying menunjukkan bahwa HO ditolak dan Ha diterima.

H4: Emosi positif berpengaruh tidak signifikan memediasi hubungan antara hedonic shopping terhadap impulse buying pada konsumen toko fashion di Kota "X". Pengaruh yang tidak signifikan dari emosi positif sebagai mediasi antara hedonic shopping terhadap impulse buying konsumen menunjukkan emosi positif yang meliputi rasa senang, puas, semangat dan nyaman yang dialami konsumen saat berbelanja tidak menunjang hedonic shopping dalam membentuk impulse buying konsumen dalam pembelian pakaian pada toko fashion.

Penelitian ini tidak sejalan dengan hasil penelitian yang dikemukakan oleh Rachmawati (2009) bahwa dalam melakukan hedonic shopping akan cenderung lebih berpengaruh terhadap impulse buying bila didukung oleh emosi positif yang kuat dari konsumen saat berbelanja.

\section{KESIMPULAN DAN IMPLIKASI}

\section{Kesimpulan}

Berdasarkan hasil penelitian dalam pembahasan tersebut, maka dapat ditarik simpulan sebagai berikut: (1) Variabel Hedonic Shopping berpengaruh signifikan terhadap impulse buying pada konsumen yang berbelanja pakaian pada toko fashion di Kota "X". Semakin tingginya pembelian dikarenakan rasa suka akan produk pakaian dan pembeli yang suka dengan model pakaian terbaru akan memicu konsumen untuk melakukan pembelian impuls pada produk pakaian. Dengan demikian maka hedonic shopping konsumen sudah tepat sasaran untuk mendukung pembelian impuls konsumen terhadap produk pakaian; (2) Hedonic shopping berpengaruh signifikan terhadap emosi positif pada konsumen yang berbelanja pakaian pada toko fashion di Kota "X". Konsumen dengan hedonic shopping akan menunjukkan rasa senang, 
puas, nyaman dan bersemangat (emosi positif) yang tinggi dalam berbelanja pakaian di toko fashion; (3) Variabel Emosi Positif tidak berpengaruh signifikan terhadap impulse buying pada konsumen yang berbelanja pakaian pada toko fashion di Kota "X". Semakin lengkapnya pakaian yang dijual serta sarana yang tersedia sehingga akan mampu memicu emosi positif konsumen untuk berbelanja. Sehingga emosi positif konsumen sudah tepat sasaran untuk mendukung pembelian impuls konsumen terhadap produk pakaian pada toko fashion di Kota "X"; dan (4) Variabel Emosi Positif tidak berpengaruh signifikan memediasi hubungan antara Hedonic Shopping terhadap impulse buying pada konsumen yang berbelanja pakaian pada toko fashion di Kota "X", artinya emosi positif sebagai variabel mediasi tidak mendukung hedonic shopping terhadap variabel impulse buying pada konsumen yang berbelanja pakaian.

\section{Implikasi}

Penelitian mendatang diharapkan: (1) Pemilik toko perlu mempertimbangkan sarana dan prasarana yang tersedia di dalam toko agar dapat menarik konsumen lebih betah berbelanja yang memungkinkan konsumen senang dan ada niat untuk kembali berbelanja (misalnya dengan adanya AC sehingga pembeli tidak kepanasan, menata barang-barang dagangannya agar pembeli bisa dengan leluasa mencari kebutuhannya) dan mengetahui kesukaan konsumen akan jenis dan model pakaian dan selalu menyediakan produk-produk terbaru, ter-update yang diincar pembeli saat berbelanja; (2) Pemilik toko fashion dapat meningkatkan emosi positif konsumen dengan memperhatikan berbagai segi yang terlihat sangat menyenangkan bagi konsumen yang telah terbukti berpengaruh terhadap impulse buying pada konsumen saat berbelanja dimana konsumen tidak lagi mempertimbangkan waktu dan uang yang dikorbankan untuk memperoleh pakaian yang diinginkan karena lebih pentingkan rasa senang dan puasnya saat berbelanja; dan (3) Sebaiknya perlu melakukan modifikasi terhadap model penelitian dan hipotesis guna mencari faktor-faktor lain yang dapat memengaruhi konsumen melakukan pembelian impuls, misalnya dengan menggunakan variabel situasional atau personal konsumen atau faktor-faktor lain yang belum diteliti dalam penelitian ini.

\section{DAFTAR PUSTAKA}

Dewi, N. R., Suharyono., dan K. Srikandi. (2015). Pengaruh Fashion Involvement dan Kecenderungan Hedonic Consumption Dengan Mediator Emosi Positif Terhadap Pembelian Impulsif Berorientasi Fashion (Survei Pada Pembeli Pakaian Di Mall Olympic Garden Kota Malang). Jurnal Administrasi Bisnis (JAB) Volume 26, Nomor 2, (1-10).

Hawkins, D. I., David, L., and Mothers B. (2014). Consumer Behavior: Building Marketing Strategy, Twelfth Edition. McGraw-Hill Education, 2 Penn Plaza, New York.

Jemli, K. (2013). Consommation de mode chez les adolescents: Rôle des processus identitaires. La Revue Gestion Et Organisation Volume 5, (62-70). 
Kosyu, D. A., Hidayat, K., dan Abdillah Y. (2014). Pengaruh Hedonic Shopping Motives Terhadap Shopping Lifestyle dan Impulse Buying (Survei pada Pelanggan Outlet Stradivarius di Galaxy Mall Surabaya). Jurnal Administrasi Bisnis (JAB), Volume 14, Nomor 2, (1-7).

Mohan, G., B. Sivakumaran., and P. Sharma. 2013. Impact of Store Environment on Impulse Buying Behavior. European Journal of Marketing. Volume 47, Nomor 10.

Park, E. J., E. Y. Kim., and J. C. Forney. 2006. A Structural Model of Fashion-Oriented Impulse Buying Behavior. Journal of Fashion Marketing and Management Volume 10, Nomor 4, (433-446).

Park, J., and S. J. Lennon. (2005). Psychological and Environmental Antecedents of Impulse Buying Tendency in the Multichannel Shopping Context, Journal of Consumer Marketing. Volume 23, Nomor 2, (56-66).

Pattipeilohy, V. R., Rofiaty., and M. S. Idrus. (2013). The Influence of the Availability of Money and Time, Fashion Involvement, Hedonic Consumption Tendency and Positive Emotions Towards Impulse Buying Behavior in Ambon City (Studi on Purchasing Products Fashion Apparel). International Journal of Bussiness and Behavioral Sciences, Volume 3, Nomor 8, (36-49).

Rachmawati, V. (2009). Hubungan Antara Hedonic Shopping Value, Positive Emotion, dan Perilaku Impulse Buying Pada Konsumen Ritel. Majalah Ekonomi Tahun XIX, Nomor 2, (192-209).

Rieke, S. E., D. C. Fowler., H. J. Chang., and N. Velikova. (2016). Exploration of factors influencing body image satisfaction and purchase intent: Millenials females. Journal of Fashion Marketing and Management: An International Journal, Volume 20, Nomor 2.

Samuel, H. (2005). Respons Lingkungan Berbelanja Sebagai Stimulus Pembelian Tidak Terencana pada Toko Serba Ada (Toserba) (Studi Kasus Carrefour Surabaya). Jurnal Manajemen dan Kewirausahaan, Volume 7, Nomor 2, (152-170).

Saran, R., S. Roy., and R. Sethuraman. (2016). Personality and Fashion Consumption: A Conceptual Framework In The Indian Context, Journal of Fashion Marketing and Management: An Internasional Journal, Volume 20, Nomor 2, (157-176).

Verplanken, B., and Sato A. (2011) The Psychology of Impulse Buying: an Integrative selfregulation Approach. Journal of Consumer Policy, Volume 32, Nomor 4, (197-210).

Weinberg, P., and W. Gottwald. 1982. Impulsive Consumer Buying as a Result of Emotion. Journal of Business Research, Nomor 10, (43-57). 